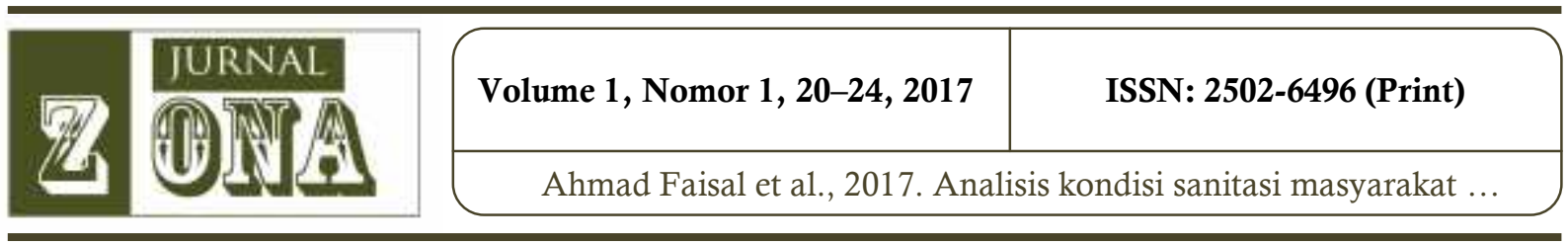

\title{
Analisis kondisi sanitasi masyarakat pinggir sungai dengan pendekatan studi EHRA di
} Kelurahan Tembilahan Kota

\author{
Ahmad Faisal $^{1}$, Zulfan Saam $^{2}$, Elda Nariati $^{3}$ \\ ${ }^{1,2}$ Pascasarjana Ilmu Lingkungan Program Pascasarjana Universitas Riau. \\ ${ }^{3}$ Fakultas Kedokteran Universitas Riau.
}

\begin{abstract}
Indragiri Hilir is low lan areas or riverbank is swamp, which has a many rivers and stream. Riverbank area there are many settlements with spesific conditions of sanitation facillities, This study uses the method of approach through studies EHRA by conducting explorative survey to look at the household scale sanitary conditions. variable research is a sanitary garbage, latrines, household waste and clean water. Sampling technique using a random sampling of the population of people who live on the riverbank with the inclusion criteria of 493 households, obtained a sample of 125 housewives. The results showed that the sanitary conditions of communities riverbank in the village Tembilahan cities include: community do not do waste treatment and immediately throw it into the river, sanitary latrines still use the river as a defecation, people immediately dispose of household waste into the river, meeting the needs of clean water to eat and drink is obtained from sources rainwater as well as for bathing and washing using river water. Communities riverbank in the village Tembilahan cities categorized as moderate risk areas . public sanitation on communities riverbank in the village Tembilahan cities do not have basic sanitation standards and the need for a proper settlement.
\end{abstract}

\section{Keywords: Garbage, Latrine, Household Waste, Study EHRA}

Rencana Pembangunan Jangka Menengah Nasional (RPJMN) Tahun 2015 - 2019 pada Direktorat Jendral Cipta Karya mewujudkan pemukiman di perkotaan yang layak huni dan berkelanjutan melalui prakarsa $100-0-100(100 \%$ akses air minum, 0\% kawasan pemukiman kumuh, 100\% akses sanitasi layak). Hal ini merupakan tugas yang sangat penting untuk ditangani secara bersama pemerintah dan masyarakat.

Kabupaten Indragiri Hilir dikenal dengan negeri seribu parit karena memiliki banyak anak sungai dan parit yang melalui beberapa kecamatan dan desa. Kondisi tersebut menjadi tempat bermukimnya sebagian masyarakat karena berhubungan dengan trasportasi laut untuk angkutan orang dan barang dan menjadi mata pencarian sebagai nelayan. Sungai juga dimanfaatkan sebagai sumber air untuk kebutuhan sehari- hari baik mencuci, mandi oleh masyarakat dan digunakan juga sebagai sumber air baku oleh perusahaan air minum daerah (PDAM) di Kabupaten Indragiri Hilir (Bappeda, 2011).

Kelompok kerja air minum dan penyehatan lingkungan (Pokja AMPL) Kabupaten Indragiri Hilir (2013) meyebutkan kondisi sanitasi yang belum baik salah satu penyebabnya adalah kondisi wilayah perairan pesisir pasang surut dan dataran rendah sehingga masyarakat merasa sulit untuk membangun sarana sanitasi jamban yang memenuhi syarat kesehatan. Data Pokja AMPL Kabupaten Indragiri Hilir mencatat 39 persen penduduk yang mengakses sanitasi layak, selebihnya masih buang air besar sembarangan dan kajian studi EHRA Tahun 2014 didapatkan 27\% keluarga yang memiliki jamban sehat dan $2.7 \%$ memiliki tangki septik tidak aman, kondisi tersebut masih jauh dari target Milinium Development Goals (MDGs) Tahun 2015 tentang sarana sanitasi sebesar 70\%.

Sebagai salah satu kajian dalam pembuatan dokumen dalam pembangunan sanitasi di Kabupaten Indragiri Hilir, melalui satuan kerja Dinas Kesehatan melakukan kajian studi enviromental healt risk assessmen (EHRA) yaitu salah satu metode studi primer yang dilakukan di Tahun 2014 dengan jumlah sampel 25 desa. Satu desa terdiri dari $40 \mathrm{ibu}$ rumah tangga bertujuan mengetahui tentang ketersediaan layanan sanitasi pada suatu daerah ditingkat rumah tangga, Adapun objek studi meliputi limbah cair rumah tangga, limbah padat/ persampahan, drainase serta prilaku hidup bersih dan sehat termasuk cuci tangan pakai sabun.

Penelitian ini bertujuan untuk mengetahui kondisi sanitasi sampah, jamban keluarga, limbah dan air bersih masyarakat pinggir sungai dan seberapa besar Indeks resiko sanitasi kesehatan lingkungan 
masyarakat pesisir dan pinggir sungai di Kelurahan Tembilahan Kota serata menganalisis tentang kondisi sanitasi sesuai dengan persyaratan pemukiman sehat menurut ketentuan yang berlaku.

\section{METODOLOGI PENELITIAN}

Penelitian ini dilaksanakan pada bulan Agustus 2015 di Kelurahan Tembilahan Kota Kabupaten Indragiri Hilir dengan metode survey terhadap masyarakat pinggir sungai. Teknik pengumpulan data dilakukan dengan metode survey terhadap masyarakat pinggir sungai melalui wawancara menggunakan kuisioner dan pengamatan menggunakan lembaran panduan pengamatan.

Tahapan pertama dalam penelitian ini adalah mengumpulkan data-data hasil survei yang sudah terhimpun melalui kuisioner dan lembaran obserpasi, kemudian dilanjutkan dengan melakukan pengentrian data melalui program $D O S B O X$ yang berisikan software format epi info.

Hasil dan penyajian sanitasi data melalui perangkat Lunak syntak SPSS, dilakukan cleaning data sehingga menghasilkan beberapa Tabel Analisis Crosstab, Data yang dihasilkan dalam penyajian dari hasil interprestasi SPSS bentuk tabel sanitasi sampah, jamban, limbah dan air bersih dan di sajikan dalam bentuk table dan narsinya.

Tahap kedua melakukan perhitungan Indek Resiko Sanitasi melalui output tabel terakhir Tabel Indeks Resiko pada SPSS dengan secara otomatis akan menampilkan Grafik Indeks Resiko Sanitasi,yang mana hasil tersebut diperoleh dari penjumlahan komulatif setiap variabel sanitasi sumber air, air limbah domestik, persampahan, genangan air serta perilaku hidup bersih dan sehat sehingga diperoleh angka yang disesuaikan dengan katalok IRS sehingga mempermudah dalam memberikan gambaran nilai resiko.

Tahap ketiga melakukan analisis kondisi sanitasi sampah, jamban keluarga, limbah dan air bersih masyarakat pinggir sungai yang di hubungkan dengan standar dan program kebijakan yang ada diantaranya: TTPS (2010) mengenai pendaur ulangan sampah, Opsi Sanitasi WSP (2013) tentang pengolahan tinja daerah pesisir dan standar persyaratan Peraturan Menteri Kesehatan Nomor 492 Tahun 2010 tentang air minum bagi masyarakat.

\section{HASIL DAN PEMBAHASAN}

Hasil penelitian terhadap $123 \mathrm{ibu}$ rumah tangga yang tinggal dipinggir sungai di Kelurahan Tembilahan Kotaerikut ini adalah kondisi sanitasi masyarakat pinggir sungai di Kelurahan tembilahan Kota diperoleh gambaran dasar,39\% usia ibu rumah tangga diatas 45 tahun, 35,8\% berprndidikan sekolah dasar dan 59\% rumah milik sendiri.

\section{Sanitasi Masyarakat Pinggir Sungai}

Gambaran pengolahan sampah setempat rumah tangga masyarakat pinggir sungai di Kelurahan Tembilahan kota sebahagian besar (66 \%) tidak melakukan pengolahan, langsung dibuang kesungai. Kondisi sampah di lingkungan rumah tangga menyatakan bahwa $(66,7 \%)$ menyatakan tumpukan sampah mengakibatkan banyak tikus yang berkeliaran, $74,8 \%$ menyatakan banyak nyamuk dan $78 \%$ anak anak banyak bermain di sekitarnya.

Kondisi tersebut memberikan gambaran yang sama dengan pernyataan Rochgiyati (2011) bahwa karena sungai memiliki status umum atau disebut juga tidak bertuan sehingga sering dimanfaatkan sebagai tempat pembuangan sampah atau limbah padat ataupun cair sehingga potensi untuk terjadi pencemaran sangatlah memungkinkan.

Tempat buang air besar anggota keluarga rumah tangga masyarakat pinggir sungai di Kelurahan Tembilahan Kota terbanyak adalah membuang ke sungai yaitu 74 rumah tangga (60,2\%).dan tempat penampungan pembuangan akhir tinja rumah tangga masyarakat pinggir sungai terbanyak dibuang ke sungai yaitu sebanyak 82 rumah tangga (66.7\%).

Kondisi sarana sanitasi jamban masyarakat pinggir sungai di Kelurahan Tembilahan Kota memberikan gambaran yang sama dengan pernyataan dari hasil survei kalangan Akademisi Fakultas 
Teknik Universitas Tidar Magelang dalam Pramono dan Widodo (2012) menyebutkan kebiasaan warga desa yang bermukim di tepi sungai menggunakan sungai sebagai tempat buang air besar.

Besaran uji statistik koefisien korelasi umur ibu rumah tangga, tingkat pendidikan dan kepemilikan rumah dengan kebiasaan buang air besar ke sungai dan kejamban tidak menunjukan hubungan bermakna karena nilai siqnifikan kurang dari 1. Hal tersebut sejalan dengan pernyataan Sukawati dan Dwipayana (2012) bahwa, faktor resiko yang tidak signifi kan terhadap ketersediaan septic tank dan pemanfaatan sarana sewerage system adalah tingkat pengetahuan, tingkat pendidikan, tingkat penghasilan, kepadatan penghuni rumah, status kepemilikan rumah, letak rumah dengan kali, dan luas halaman rumah. Jamban yang dibangun dekat dengan kali berpotensi 8,733 kali tidak memiliki sarana septic tank dan limbah tinja tersebut dialirkan ke kali, menunjukan ada hubungan jarak jamban dan kali terhadap ketersediaan septic tank dan pemanfatan sarana sewerage system,.

Pengolahan air limbah domestik yaitu 96 rumah tangga (78\%), limbah domestik langsung dibuang ke permukaan tanah atau badan air tanpa melakukan pengolahan.

Menurut Putro (2011), mengenai gambaran umum pemukiman di pinggir sungai merupakan kondisi eksisting kawasan kumuh tentang kondisi drainase dan air limbah dimana untuk daerah yang memiliki drainase limbahnya dibuang ke riol-riol sedangkan yang tidak memiliki drainase langsung membuang ke tanah dan sungai.

Sumber air dan kegunaan yang digunakan masyarakat pinggir sungai untuk minum atau masak yang paling banyak yaitu menggunakan air hujan 119 rumah tangga (96.7\%), sedangkan untuk mencuci piring sebahagian besar menggunakan sir sungai yaitu 94 rumah tangga (76.4\%).

Putro (2011) mengatakan mengenai gambaran umum pemukiman di pinggir sungai merupakan kondisi ekstisting kawasan kumuh tentang kondisi sarana air bersih di daerah kawasan yang kumuh.

\section{Indek Resiko Sanitasi}

Indeks resiko sanitasi masyarakat pinggir sungai di Kelurahan Tembilahan Kota Tahun 2015 yaitu sebesar 210. Didalam kategori daerah beresiko sanitasi Kelurahan Tembilahan Kota termasuk daerah beresiko sanitasi sedang. Jumlah angka tertinggi yaitu Air limbah domestik menunjukan kondisi yang paling beresiko dan prioritas untuk dilakukan penanganan.

Hasil survei dan penelitian ini dapat dijadikan salah satu informasi ilmiah dan data faktual tentang ketersediaan sarana sanitasi sekala rumah tangga masyarakat pinggir sungai di Kelurahan Tembilahan Kota, sebagai salah satu referensi dalam perencanaan pembangunan sanitasi daerah perkotaan dalam penyusunan dokumen strategi sanitasi kabupaten.

\section{Analisis Kondisi Sanitasi}

Sebesar $75 \%$ masyarakat pinggir sungai belum melakukan pengelolaan sampah mulai dari pengumpulan dan pengolahan skala rumah tangga, masih membuang sampah sembarangan (kesungai dan tanah kosong). Pengolahan sampah belum baik sesui petunjuk TTPS (2010) bahwa; pengumpulan dan pendaurulangan sampah di awali dengan sistem koleksi sampah mengunakan truk, gerobak yang memenuhi kaidah lingkungan.

Pembinaan pemerintah melalui satker terkait kepada kelompok masyarakat rukun tetangga (RT) maupun dasawisma membentuk pengelolaan sampah swadaya yang dikelola masyarakat itu sendiri, dapat berupa pungutan untuk penangaan sampah sekala rumah tangga. Peran pemerintah di sini dapat sebagai pembina, pengawas dan memberikan sarana prasarana serta stimulan yang berkaitan dalam pengelolaan sampah pada tahap sumber.

Kondisi jamban keluarga masyarakat pinggir sungai sesuai bahwa 65\% belum memiliki jamban dan $75 \%$ penampungan akhir tinjanya langsung ke sungai. Kondisi tersebut belum baik karena tidak memiliki tangki septik sesuai dengan sistem alternatif rumah panggung dan darat di pinggir sungai menurut WSP (2013), ada beberapa pilihan baik pribadi maupun bersama diantaranya: tangki septik fiberglass, Tripikon-S atau T-Pikon-H dan system perpipaan 
Upaya untuk mengatasi permasalahan tersebut dapat dilakukan oleh masyarakat itu sendiri melalui proses penyadaran yang dilakukan oleh instansi melalui penyuluhan dan pemicuan, Penguatan ekonomi juga dapat dilakukan melalui gotong royong maupun kerjasama pemerintah dan masyarakat melalui pemberian stimulan. Pemerintah juga dapat merencanakan pembangunan pembuatan MCK-Plus melalui dana APBD maupun sharing dana APBN serta pembangunan septik tank komunal yang dapat di pergunakan bersama oleh masyarakat.

Disamping perencanaan pembangunan infrastruktur, upaya penyadaran dan pemberdayaan masyarakat dalam perubahan perilaku tidak buang air besar sangatlah penting salah satu upayanya adalah pelaksanaan pemicuan. Menurut Permenkes No 3 Tahun 2014 mengatakan bahwa: pemicuan adalah salah satu cara untuk mendorong perubahan perilaku masyarakat atas kesadaran sendiri dengan menyentuh perasaan, pola pikir, perilaku dan kebiasaan individu atau masyarakat. Keberhasilan tersebut ditunjukan dengan meningkatnya akses sanitasi sebesar 23 \% di 29 kabupaten di Jawa Timur Tahun 2011.

Kondisi pengolahan limbah cair rumah tangga yaitu 78\% masyarakat pinggir sungai tidak memiliki sarana pengolahan air limbah, baik berupa saluran maupun tangki septik. Kondisi tersebut belum baik, menurut Menurut Tim Teknis Pembangunan Sanitasi Bapennas (2010), Drainase merupakan suatu saluran air buangan dari limbah domestik dengan menggunakan sistem aliran Drainase makro dapat berupa sungai, saluran primer dan sekunder dan biasa dikelola secara tradisional untuk irigasi dan berfungsi sebagai tempat pembuangan dan pengaliran grey water dan bahkan black water oleh kawasan pemukiman.

Sumber air bersih masyarakat pinggir sungai bahwa, 97\% masyarakat menggunakan air hujan untuk minum dan cuci serta $60 \%$ menggunakan air sungai untuk mencuci. Kondisi tersebut belum memenuhi syarat menurut permenkes 492 Tahun 2010 bahwa, air bersih harus memenuhi syarat baik kualitas maupun kuantitas.

Penyediaan sarana air bersih dapat dilakukan melalui PDAM dengan menambah layanannya, juga dapat dilakukan pemerintah melalui dana APBD maupun sharing APBN seperti dalam Program Sanimas ataupun Pamsimas. Akses air bersih dengan biaya terjangkau akan dapat dirasakan masyarakat dan tersedia hidran umum untuk masyarakat kurang mampu.

\section{KESIMPULAN}

Hasil penelitian yang dilakukan pada masyarakat pinggir sungai di Kelurahan Tembilahan Kota Tahun 2015 menggambarkan, kondisi sarana sanitasi yaitu sebahagian besar masyarakat belum melakukan pengolahan sampah dan membuang sampah langsung ke sungai, sanitasi jamban masih menggunakan sungai sebagai tempat buang air besar dan tempat penampungan akhir tinja, sebahagian besar masyarakat belum melakukan pengolahan limbah cair rumah tangga baik berupa saluran maupun tempat penampungan limbah cair dan langsung dibuang ke sungai dan pemenuhan kebutuhan air bersih untuk makan dan minum diperoleh dari sumber air hujan dan untuk kebutuhan mandi, cuci menggunakan air sungai.

Tingkat Indeks Resiko Sanitasi masyarakat pinggir sungai di Kelurahan Tembilahan Kota di kategorikan sebagai daerah beresiko sanitasi sedang. Sanitasi masyarakat pinggir sungai di Kelurahan Tembilahan Kota belum memenuhi standar dan kebutuhan sanitasi dasar di pemukiman yang layak karena kurangnya ketersediaan sarana pengolahan limbah, sanitasi jamban dan perilaku pembuangan sampah ke sungai secara terus - menerus mengakibatkan terjadinya eutropikasi yang berdampak kepada gangguan species dan penurunan kualitas air sungai.

\section{UCAPAN TERIMAKASIH}

Penulis menyampaikan terimakasih kepada seluruh pihak yang membantu dalam kelancaran penelitian ini.

\section{DAFTAR PUSTAKA}

Program PPSP. 2014. Panduan Praktis Pelaksanaan EHRA (Unvironmental Health Risk Assessmen/ Penilaian Resiko Kesehatan karna Lingkungan). Kementerian kesehatan RI. Dirjen PP dan PL. Jakarta

Sukawati.I. D,.G., N M U Dwipayanti. 2012. Faktor Pengaruh Terhadap Ketersediaan Septictank dan Sambungan Sewerage System Permukiman Pinggiran Kali, Kel. Dangin Puri, Denpasar. Program Studi 


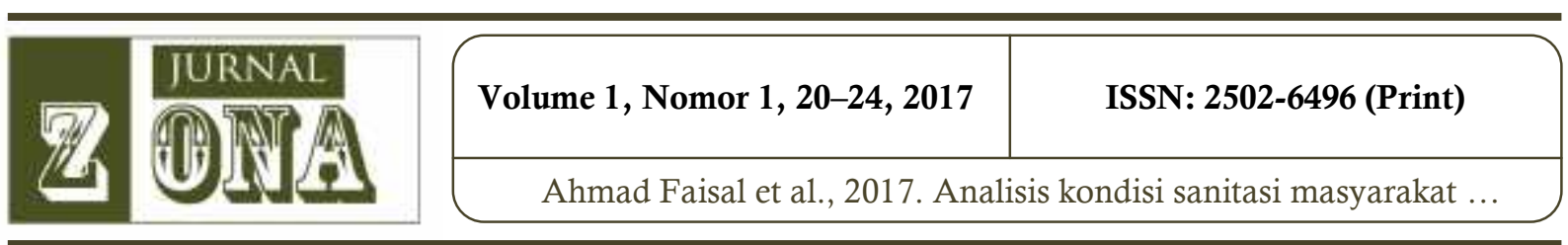

Ilmu Kesehatan Masyarakat, Fakultas Kedokteran, Universitas Udayana, Denpasar-Bali 1 (1): 55 62 .

Tim Teknis Pembangunan Sanitasi (TTPS). 2010. Buku Referensi Opsi Sistem dan Teknologi Sanitasi. Badan Perencanaan Pembangunan Nasional. Jakarta. 